\title{
Changes in Size, Subclass, and Metabolic Properties of Serum Immunoglobulin A in Liver Diseases and in Other Diseases with High Serum Immunoglobulin A
}

\author{
D. L. Delacroix, K. B. Elkon, A. P. Geubel, H. F. Hodgson, C. Dive, and \\ J. P. Vaerman, Unit of Gastroenterology, Cliniques Universitaires St.-Luc \\ and Unit of Experimental Medicine, International Institute of \\ Cellular and Molecular Pathology, Université Catholique de Louvain, \\ Brussels; Department of Medicine, Royal Postgraduate \\ Medical School, London, England
}

A B STRACT We have studied the relative contributions of monomeric (m-) and polymeric IgA (p-IgA) and of IgAl and IgA2 to total serum IgA in healthy adults and patients with liver disease (LD) or with other diseases and high serum IgA. Serum concentration of total secretory component (SC) was also determined. In addition, fractional catabolic rates (FCR) and synthetic rates for both $\mathrm{m}$ - and p-IgA were measured in nine controls and nine cirrhotics. Our results support four main conclusions: (a) In healthy adults, intravascular p-IgA contributes to only $4-22 \%$ (mean $12 \%$ ) of serum IgA, because its FCR and synthetic rate are approximately two times higher and four times smaller, respectively, than those of intravascular mIgA. (b) In LD, biliary obstruction does not result in a significant increase in serum p-IgA unlike in rats and rabbits, indicating that in humans the SC-dependent biliary transport of p-IgA plays a much less significant role in selective removal of $\mathrm{p}$ - IgA from plasma than in rats and rabbits. $(c)$ In contrast to biliary obstruction, parenchymal LD results in a significant and preferential increase in serum p-IgA, which in cirrhotics correlates with a selective reduction of the p-IgA-FCR. This supports a role for the human liver in selective removal of p-IgA from plasma, but another mechanism than the SC-dependent biliary transport should be considered. (d) Total SC, p-IgA, and IgA2 in serum are unlinked parameters, not necessarily reflecting mucosal events. A marked increase in serum SC occurs

Address reprint requests to Dr. Delacroix, ICP-MEXP, Brussels, Belgium.

Received for publication 17 May 1982 and in revised form 13 October 1982. almost selectively in LD. Although a shift to IgA2 is suggested in Crohn's disease and alcoholic cirrhosis, a shift to IgAl frequently associated to a shift to $\mathrm{p}-\operatorname{IgA}$ occurs in chronic active LD, primary Sicca, and connective tissue diseases.

\section{INTRODUCTION}

Human IgA occurs in both monomeric $(m-\operatorname{IgA})^{1}$ and polymeric J-chain containing (p-IgA) forms $(1,2)$, and comprises two subclasses, IgA1 and IgA2 (3-5). In normal individuals, $\mathrm{p}$-IgA bound to secretory component (SC) predominates in secretions, whereas in serum 80 $90 \%$ of IgA are monomeric and most of p-IgA is devoid of SC $(1,2)$. Secretions and serum also differ by their proportion of subclasses, with $\sim 40 \%$ of IgA2 in secretions vs. $20 \%$ in serum $(6,7) . S C$ is an epithelial cell glycoprotein that acts as a membrane receptor for $p$ $\operatorname{IgA}$ and IgM at the basolateral surface of the mucosal epithelial cells. It allows the vesicular transcytoplasmic transport of p-IgA and IgM into secretions $(8,9)$.

Increased concentrations of IgA in serum occur in various diseases $(1,2)$ but little is known on the size and subclass of IgA involved in these elevations. In cirrhosis, a preferential increase in the proportion of

${ }^{1}$ Abbreviations used in this paper: A Hep, acute hepatitis; Al C, alcoholic cirrhosis; B Obst, biliary obstruction; CALD, chronic active liver disease; $\mathrm{d}$-IgA, dimeric IgA; FCR, fractional catabolic rate(s);. IJBP, ileojejunal bypass; IRMA, immunoradiometric assay; LD, liver disease(s); m-IgA, monomeric IgA; PBC, primary biliary cirrhosis; PBS, phosphatebuffered saline; p-IgA, polymeric IgA; RA, rheumatoid arthritis; SC, secretory component; SDGU, sucrose density gradient ultracentrifugation; sIgA, secretory IgA; SLE, systemic lupus erythematosus. 
p-IgA was found $(1,10,11)$, whereas conflicting results regarding serum p-IgA in Berger's disease exist (1214). Some experimental (15) and clinical evidence (16, 17) suggests that p-IgA may be directly involved in tissue injury in some diseases. Changes in subclass proportions in pathological sera have not been studied but there are conflicting data about the IgA subclass deposits in Berger's disease $(13,18,19)$.

Minute amounts of SC occur in serum (20), always bound to p-IgA and/or $\operatorname{IgM}(21,22)$ with virtually undetectable free SC unlike in secretions $(21,22)$. Although p-IgA, IgA2, and SC in serum have been considered as possible indices of mucosal events, it is not known whether a positive correlation between these three serum parameters occurs in disease.

It seemed likely that differences in tissue origins and metabolic fate of serum IgA in various diseases would be associated with distinct patterns regarding $\mathrm{m}$-IgA, p-IgA, IgA1, IgA2, and SC in serum. We therefore undertook a comparative study of these parameters in some systemic, mucosal, liver, and kidney diseases with elevated total serum IgA. We also compared the metabolic properties of $\mathrm{m}$ - and $\mathrm{p}$-IgA in normal individuals and in patients with liver diseases (LD) to assess further the role of the liver in the metabolism of circulating IgA.

\section{METHODS}

Patients and controls. We analyzed the sera of 204 caucasian adults not submitted to any immunosuppressive therapy. Controls $(n=34)$ were clinically healthy volunteers with a mean age of $41 \mathrm{yr}(24$ to $68 \mathrm{yr})$. Four main groups of patients were studied. (a) LD were classified as previously described (23) and included (i) chronic active LD (CALD, $n=34$; hepatitis $\mathrm{B}$ antigen positive, $n=14$ ) comprising chronic active hepatitis $(n=7)$ and postnecrotic cirrhosis $(n=27) ;(i i)$ alcoholic cirrhosis (Al C, $n=37$ ); (iii) primary biliary cirrhosis (PBC, $n=13$ ); (iv) tumoral complete extrahepatic biliary obstruction (B Obst, $n=14$ ) demonstrated by retrograde endoscopic- or transhepatic-cholangiography; (v) acute hepatitis (A Hep, $n=13$ ) with submassive or massive necrosis of the liver in five cases. (b) Connective tissue diseases $(n=30)$ comprised definite or classical rheumatoid arthritis (RA, $n=7$ ), systemic lupus erythematosus fulfilling four or more acute RA criteria (SLE, $n=13$ ) and primary Sicca syndrome (Sicca, $n=10$ ) associated with systemic symptomatology as described previously (24). (c) Intestinal diseases $(n=18)$ comprised active Crohn's disease (Crohn, $n=12$ ) and ileojejunal bypass (IJBP, $n=6)$; (d) IgA nephropathy (Berger's disease, $n=11$ ) diagnosed on the basis of focal mesangial glomerulonephritis with positive immunofluorescence for IgA in glomeruli in all cases. In five cases, serum was obtained together with kidney biopsy, whereas in the six other cases, serum was obtained between 1 mo to 4 yr after histological diagnosis.

All patients were unselected except for those with RA SLE, and Crohn's disease who were included, because of serum IgA levels $\geq 2$ SD above the mean of normal controls.

Total IgA and SC concentration in serum. Total IgA in serum was measured by immunonephelometry, an assay in which results are virtually unaffected by the molecular size of IgA (25). Total SC in serum was measured by the competition radioimmunoassay previously described (26) but using plastic beads rather than cups as solid phase. This assay measures all forms of SC in serum, namely SC bound to pIgA and IgM, free SC being virtually absent in all sera (21, 22). The concentrations of total SC were expressed in equivalents of $11 S \operatorname{sIgA}$, which was the standard used.

Size distribution of IgA in serum. Sera were divided in 31 fractions of $0.4 \mathrm{ml}$, after sucrose density gradient ultracentrifugation (SDGU) during $16 \mathrm{~h}$ at $38,000 \mathrm{rpm}\left(\omega^{2} \mathrm{t}\right.$ $\left.=9.11 \times 10^{11}\right)$ on isokinetic $(5-21 \%)$ gradients in a SW 41 Ti Beckman rotor (Beckman Instruments, Inc., Fullerton, CA), by downward elution under optical density monitoring (27). Buffers used were either phosphate-buffered saline, $\mathrm{pH}$ 7.4 (PBS), or 0.1 M glycine-HCl-buffered saline, pH 3.0. About $10 \mu \mathrm{g}$ of $\operatorname{IgA}(1-8 \mu \mathrm{l}$ of serum) in $0.3 \mathrm{ml}$ of buffer were applied on gradients. IgA was measured (duplicate) in SDGU-fractions numbers 6 to 25 (14 to 4 S), after at least 10 fold dilution in horse serum (1/5 in PBS), using an immunoradiometric assay (IRMA) and the correction factors for underestimation of p-IgA, as previously described (28). Standards were obtained from the same pool of normal sera as for immunonephelometry. Internal markers were ${ }^{125} \mathrm{I}$-dimeric IgA (d-IgA) (27) and the peak of IgG detected by optical density. Proportions of p-IgA were measured by planimetry.

J chain in p-IgA. The J chain-content of the serum d-IgA fractions of three patients with $>30 \%$ of p-IgA in serum was compared to that of a purified monoclonal d-IgA (27) taken as standard. Serum d-IgA was isolated after SDGU of 60 $\mu \mathrm{l}$ (in $0.3 \mathrm{ml}$ of buffer) of serum by pooling the four fractions that contained most of the d-IgA. These pools were dialyzed against $0.1 \mathrm{M}$ Tris- $\mathrm{HCl}, \mathrm{pH} 8.0$ and concentrated by vacuum ultrafiltration to $0.1 \mathrm{ml}$. The presence of J-chain was demonstrated by immunoelectrophoresis in the reduced-alkylated (10 mM dithiothreitol, $22 \mathrm{mM}$ iodoacetamide) but not in the native samples, using a specific rabbit anti-J-chain antiserum. The J-chain concentrations in the reduced-alkylated samples and the IgA concentrations in the native samples were measured by single radial immunodiffusion and expressed as a percentage of the corresponding concentration in the monoclonal d-IgA standard.

Subclass distribution of IgA in serum. IgA1 and IgA2 in serum were measured by radial immunodiffusion using specific rabbit antisubclass antisera prepared by injections of $\operatorname{IgA} 1 \lambda$, or of two IgA2 ( $\kappa$ and $\lambda$ ) proteins. Repeated solidphase absorptions of antisera were made on purified monoclonal IgA2 $\lambda$ - and IgA-deficient serum, or on two IgAl ( $\alpha$ and $\lambda$ ) myeloma sera, respectively. Specificities were demonstrated by immunoelectrophoresis, radial immunodiffusion, and radioimmunological techniques (7) using five monoclonal IgA of both subclasses. Specificity of the antiIgA2 antiserum was kindly confirmed by Dr E. van Loghem (Blood Transfusion Center, Amsterdam) using hemagglutination inhibition techniques. The same pool of serum as for IRMA was used as standard, diluted from $1 / 8$ to $1 / 80$ for IgA 1 and from $1 / 1$ to $1 / 10$ for $\operatorname{IgA2}$; it contained $21 \%$ of IgA2 by reference to two purified monoclonal $\mathrm{m}-\mathrm{IgAl}$ and m-IgA2 assayed with the total IgA IRMA and by optical density. Results were expressed as IgA2 $\times 100 /(\operatorname{IgA1}$ + IgA2). The sum of IgAl + IgA2 divided by total IgA yielded a mean ratio of $0.96 \pm 0.07$

Survivals of injected $m$-and p-IgA. Clinically healthy volunteers $(n=9$; age 24-63 yr, mean $=40)$ and patients with cirrhosis (Al C, $n=5$; postnecrotic, $n=4$; age 32-71 $y r$, mean $=51$ ) or with complete extrahepatic tumoral $B$ 


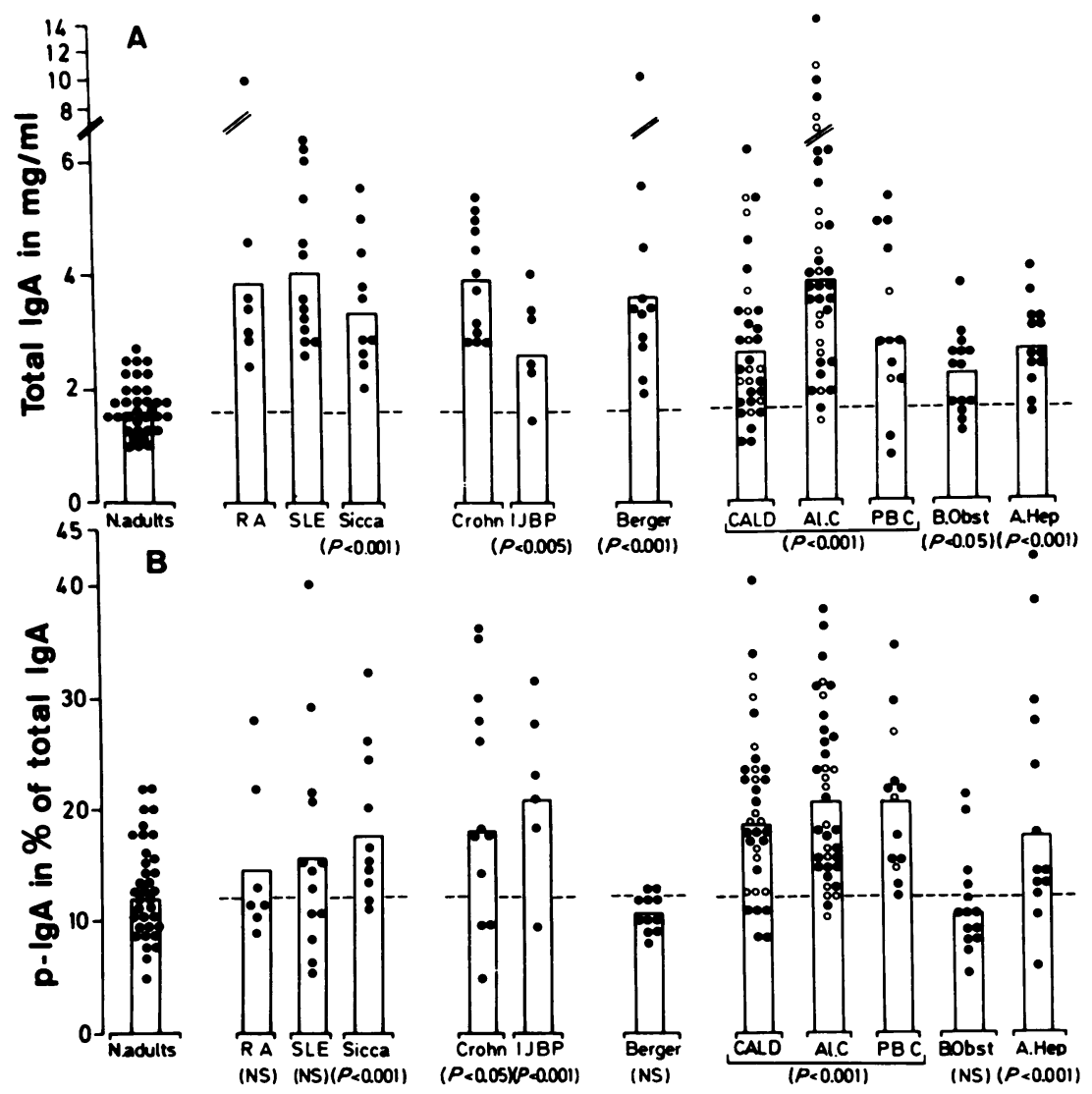

Figure 1 Individual results for total $\operatorname{IgA}(\mathrm{A}), \mathrm{p}$-IgA(B), secretory component (C) and IgA2 (D) levels or proportions in sera of the 204 adults studied. Open circles in LD are patients with a surgical portacaval shunt; logarithmic mean values are shown by columns; horizontal dashed lines: mean value of 34 normal adult controls. Significance of the differences between controls and disease are shown under each group, with NS (not significant) being $P>0.1$, except for total IgA in RA, SLE, and Crohn, because these patients were selected for their high IgA concentrations.

Obst $(n=1$, age $51 \mathrm{yr})$ were injected after informed consent with $2 \mu \mathrm{Ci}$ each of polyclonal ${ }^{125} \mathrm{I}-\mathrm{d}-\mathrm{IgA}$ and ${ }^{131} \mathrm{I}$-m-IgA. The purification and criteria of purity of these IgA proteins have been described previously (27). d-IgA was devoid of SC, able to bind free SC, and was transported with high efficiency in rat and rabbit bile (29). Its J-chain content measured by radial immunodiffusion was similar to that of purified dimeric monoclonal IgA (see above). All patients except the one with B Obst, had been in hospital for $>2 \mathrm{wk}$ before the injection and had stable serum IgA concentrations. Serum samples were obtained twice a day for $5 \mathrm{~d}$ and counted ( 2 $\mathrm{ml}$ ) for $10 \mathrm{~min}$. Fractional catabolic rates (FCR), pool masses, and absolute synthetic rates were calculated according to Matthews (30). The protocol was approved by the ethics committees of the Cliniques Universitaires St.-Luc, Brussels, and of the Hammersmith Hospital, London.

Statistical methods (31). Results in diseases were compared to those in controls by the Mann-Whitney U-test. The relative contribution of $\mathrm{p}$-IgA of IgA2 to the elevation of total IgA was compared between each individual disease with high total IgA by regression analysis of the paired parameters (absolute concentration of $\mathrm{p}$-IgA or of $\operatorname{IgA} 2$ on total
IgA) after each group had been pooled with controls. The different regression slopes were then compared by the $F$ test using appropriate numbers of degrees of freedom. FCR of m-IgA were compared to those of $p$-IgA by the Wilcoxon test for paired values, and their correlation with other parameters was calculated by arithmetic regression.

\section{RESULTS}

Total IgA in serum. Unselected patients with LD, Sicca, IJBP, and Berger's disease had significantly higher serum IgA than controls (Fig. 1A). The highest IgA concentrations were found in $\mathrm{Al} \mathrm{C}$, whereas patients with B Obst had the smallest IgA increases among the various groups of LD.

Size distribution of IgA in serum. Compared with controls with normal IgA levels, a significant increase in the proportion of p-IgA (Fig. 1B) was found in parenchymal $L D$, Sicca, and intestinal diseases. In cir- 


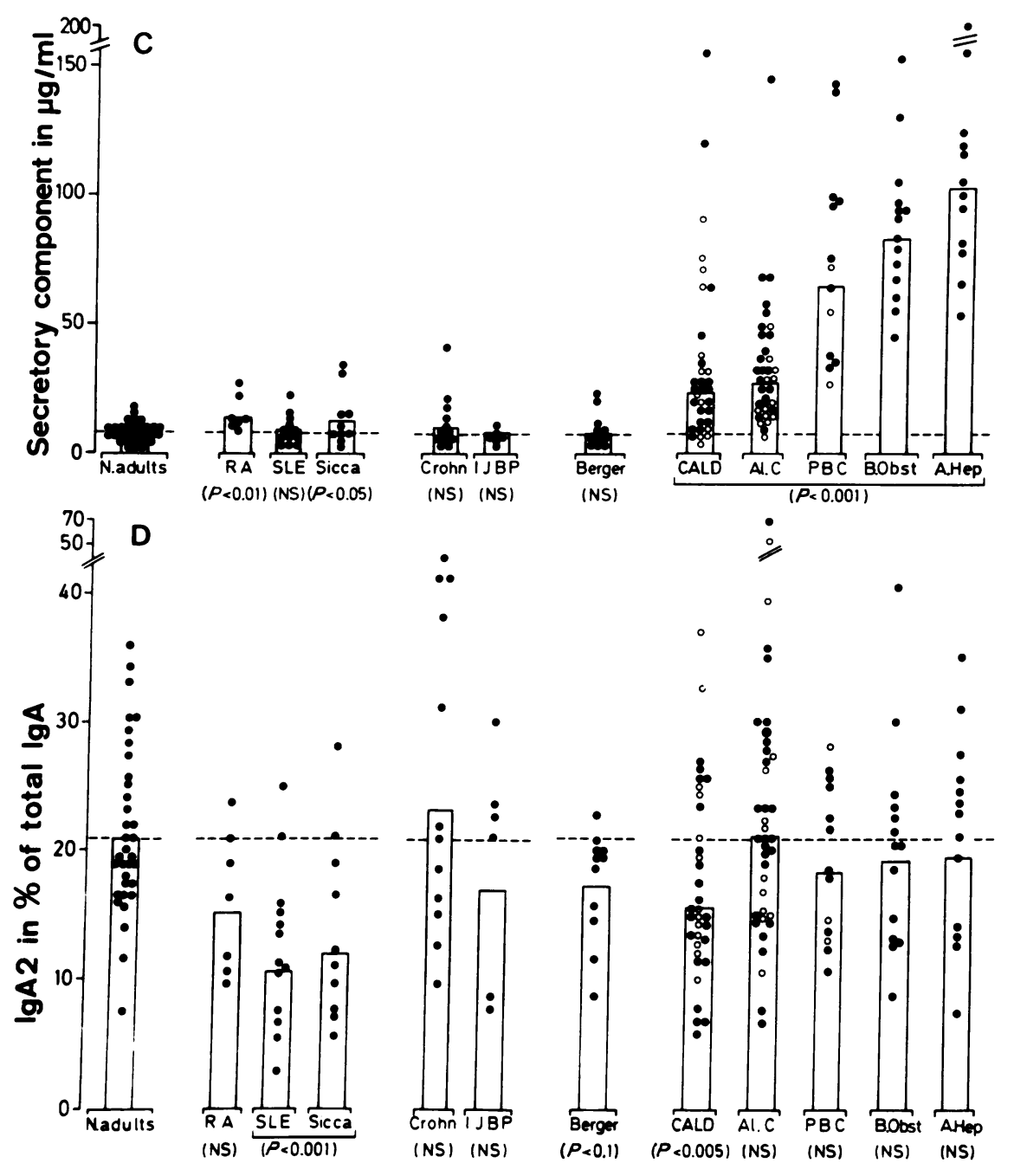

Figure 1 (Continued)

rhosis, results in patients with surgical portacaval shunt were similar to those in other patients. In Berger and B Obst, the IgA size distribution was similar to that in controls and the absolute $\mathrm{p}$-IgA concentrations were not increased in B Obst. In 24 patients with $>20 \%$ of p-IgA, no change in the proportion of p-IgA was observed when SDGU was performed at $\mathrm{pH}$ 3.0, a condition previously shown to shift the position of p-IgA rheumatoid factor to a less dense region of the gradient (32). This implied that the increase in p-IgA did not represent immune complex formation. The mean $\mathrm{p}$ $\operatorname{IgA}(\mathrm{pH} 7.4) / \mathrm{p}-\operatorname{IgA}(\mathrm{pH} 3.0)$ ratio for these 24 cases was $0.98 \pm 0.08$. Because of high levels of p-IgA rheumatoid factor in Sicca patients (32), their proportion of p-IgA was calculated from SDGU performed at pH 3.0.
TABLE I

Influence of $p H$ on Serum IgA Fractionation by SDGU, and J-chain Content in d-IgA

\begin{tabular}{|c|c|c|c|c|c|}
\hline & \multirow[b]{2}{*}{ Diagnosis } & \multirow[b]{2}{*}{$\begin{array}{c}\text { Total } \\
\operatorname{lgA}\end{array}$} & \multicolumn{2}{|c|}{$\begin{array}{c}\text { d-lgA (\% of total } \\
\operatorname{lgA})\end{array}$} & \multirow[b]{2}{*}{$\begin{array}{c}\text { Relative } \\
\text { J-chain content }\end{array}$} \\
\hline & & & $\begin{array}{c}\text { Neutral } \\
\mathrm{pH}\end{array}$ & $\begin{array}{c}\text { Acid } \\
\mathrm{pH}\end{array}$ & \\
\hline & & $m g / m l$ & & & \\
\hline 1 & PBC & 4.48 & 34 & 32 & 1.2 \\
\hline 2 & SLE & 3.26 & 41 & 42 & 0.9 \\
\hline 3 & Al. C. & 5.04 & 31 & 29 & 0.8 \\
\hline
\end{tabular}

- Relative $\mathrm{J}$-chain content $=(\mathrm{J}$-chain $/ \operatorname{IgA})$ concentration ratio in serum d-IgA, divided by the same $(J-c h a i n / \operatorname{IgA})$ ratio in the $d-\operatorname{IgA}$ monoclonal standard. 


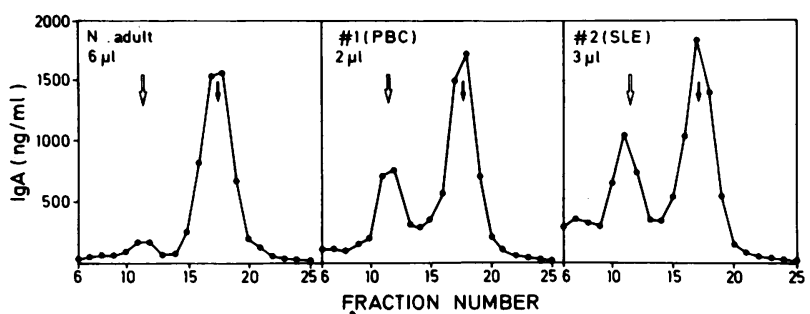

Figure 2 IgA size profile in sera of a normal adult, a patient with PBC (patient 1), and a patient with SLE (patient 2), obtained after density gradient ultracentrifugation and immunoradiometric assay. The number of serum microliters applied on the gradient is indicated. Open arrow; position of ${ }^{125} \mathrm{I}$-d-IgA marker; closed arrow; position of IgG assessed by optical density.

Results of measurements of the J-chain content in d-IgA compared to a monoclonal d-IgA standard are listed in Table I for three cases with IgA polymers comprising $>30 \%$ of the total serum IgA. The SDGUprofiles for two of these cases and for one control are shown in Fig. 2.

The relative contribution of $\mathrm{p}-\operatorname{IgA}$ to the elevated total IgA in the different disease categories (p-IgA on total IgA regression slope $\pm \mathrm{SD}$ ) was the highest in parenchymal LD $(0.22 \pm 0.01)$, Sicca $(0.23 \pm 0.02)$, Crohn $(0.22 \pm 0.03)$, and in IJBP $(0.24 \pm 0.03)$. The slopes for these diseases were significantly higher $(P<0.05)$ than those for SLE and RA $(0.15 \pm 0.02)$. The slopes for Berger and $B$ Obst $(0.10 \pm 0.02$, each) were close to that obtained for controls alone $(0.11 \pm 0.03)$. These differences are summarized in Fig. 3.

Survival of injected $m$ - and p-IgA in LD and controls. Results of survivals of ${ }^{131} \mathrm{I}-\mathrm{m}$ - and ${ }^{125} \mathrm{I}-\mathrm{p}-\mathrm{IgA}$ in cirrhotics compared to controls are listed in Table II.

In controls the FCR and synthetic rates of p-IgA were 1.8 times larger (Fig. 4) and 4 times smaller, respectively, than those of $\mathrm{m}$-IgA.

In cirrhotics, serum $\mathrm{m}$ - and $\mathrm{p}$-IgA concentrations were increased two and four times, respectively with a significant increase of both intravascular pools. In contrast to controls, the difference between FCR of $\mathrm{m}$ and p-IgA was no longer significant because of a selective reduction of the FCR of p-IgA $(P<0.005)$, with, in three cases, a FCR of p-IgA, in fact, lower than that of m-IgA (Fig. 4). The reduction of the FCR of p-IgA in cirrhosis correlated significantly $(r: 0.74$, $P<0.025)$ with the prothrombin time. In addition in this disease the increase of the intravascular pool of p-IgA correlated $(P<0.005)$ with both the decrease of the FCR and the increase of the synthetic rate of p-IgA (Fig. 5), indicating the contribution of both reduced catabolism and increased synthesis to the high serum p-IgA levels. Such correlation for $\mathrm{m}-\operatorname{IgA}$ was found only with the synthetic rate but to a less significant degree $(P<0.1)$.

In the case with complete B Obst, FCR of both $\mathrm{m}$ $(0.31)$ and p-IgA (0.55) were close to mean control values.

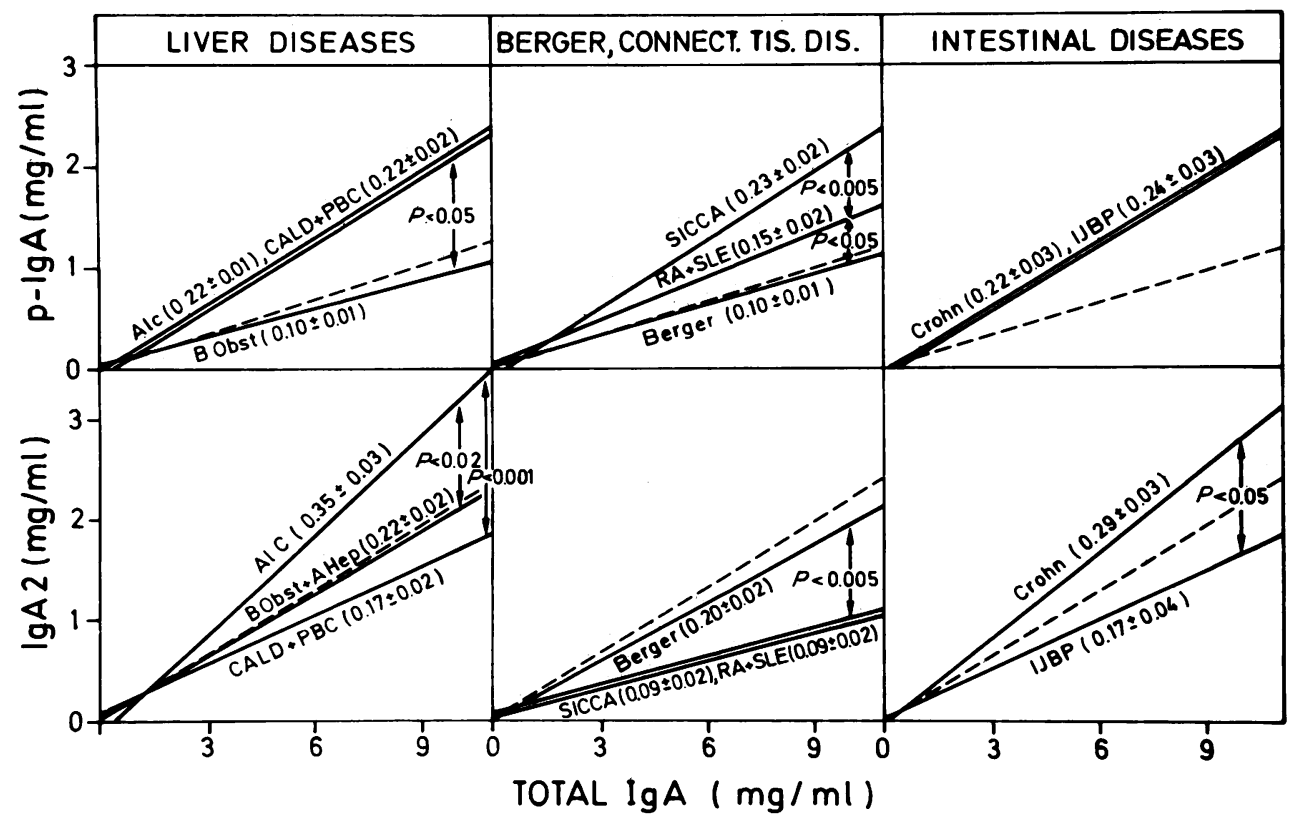

Figure 3 Regression lines of serum concentrations of p-IgA (top) or of serum IgA2 (bottom) on total serum IgA in various diseases, each pooled with the control group. In parentheses, slopes \pm SD. In A Hep, slope for p-IgA $=0.23 \pm 0.02$. The dashed lines are the projection of the regression lines in controls alone, whose slope is $0.11 \pm 0.03$ for $\mathrm{p}-\mathrm{IgA}$, and $0.22 \pm 0.05$ for IgA2. 
TABLE II

Survivals of ${ }^{131} I m$ - and ${ }^{125} I$ p-IgA in Nine Cirrhotics Compared with Nine Controls

\begin{tabular}{|c|c|c|c|c|c|c|c|}
\hline & IgA & Total pool & $\begin{array}{l}\text { Percent pool } \\
\text { intravascular }\end{array}$ & I.V. Pool & $\begin{array}{c}\text { Terminal } \\
\text { t1/2 }\end{array}$ & $\begin{array}{c}\text { Fractional } \\
\text { catabolic rate }\end{array}$ & $\begin{array}{l}\text { Synthetic rate } \\
\text { (I.V. pool) }\end{array}$ \\
\hline & $m g / m l$ & $m g / k g$ & & $\mathbf{m g} / \mathbf{k g}$ & $d$ & & $m g / k g / d$ \\
\hline \multicolumn{8}{|l|}{ m-IgA } \\
\hline Controls & $\begin{array}{c}1.7^{\bullet} \\
(1.3-2.6) \ddagger \\
P<0.01 \$\end{array}$ & $\begin{array}{c}110 \\
(53-204) \\
N^{\prime \prime}\end{array}$ & $\begin{array}{c}60 \\
(49-73) \\
P<0.05\end{array}$ & $\begin{array}{c}66 \\
(29-130) \\
P<0.05\end{array}$ & $\begin{array}{c}4.7 \\
(3.4-5.8) \\
\text { NS }\end{array}$ & $\begin{array}{c}0.26 \\
(0.19-0.35) \\
\text { NS }\end{array}$ & $\begin{array}{c}16.4 \\
(10-26) \\
P<0.05\end{array}$ \\
\hline Cirrhotics & $\begin{array}{c}3.4 \\
(1.2-5.4)\end{array}$ & $\begin{array}{c}183 \\
(70-332)\end{array}$ & $\begin{array}{c}75 \\
(66-82)\end{array}$ & $\begin{array}{c}118 \\
(51-210)\end{array}$ & $\begin{array}{c}4.2 \\
(3.1-6.3)\end{array}$ & $\begin{array}{c}0.23 \\
(0.14-0.29)\end{array}$ & $\begin{array}{c}26.0 \\
(12-40)\end{array}$ \\
\hline \multicolumn{8}{|l|}{ p-IgA } \\
\hline Controls & $\begin{array}{c}0.23 \\
(0.12-0.33) \\
P<0.01\end{array}$ & $\begin{array}{c}18.5 \\
(7-27) \\
\text { NS }\end{array}$ & $\begin{array}{c}52 \\
(46-59) \\
P<0.001\end{array}$ & $\begin{array}{c}10 \\
(3-14) \\
P<0.1\end{array}$ & $\begin{array}{c}3.0 \\
(2.8-3.5) \\
\text { NS }\end{array}$ & $\begin{array}{c}0.47 \\
(0.35-0.58) \\
P<0.005\end{array}$ & $\begin{array}{c}4.5 \\
(1.8-7.1) \\
\text { NS }\end{array}$ \\
\hline Cirrhotics & $\begin{array}{c}0.94 \\
(0.22-2.04)\end{array}$ & $\begin{array}{r}36.9 \\
(9-90)\end{array}$ & $\begin{array}{c}73 \\
(58-89)\end{array}$ & $\begin{array}{c}27 \\
(6-71)\end{array}$ & $\begin{array}{c}3.9 \\
(2.6-6.3)\end{array}$ & $\begin{array}{c}0.28 \\
(0.14-0.47)\end{array}$ & $\begin{array}{c}6.1 \\
(2.1-10.2)\end{array}$ \\
\hline
\end{tabular}

- Mean.

$\ddagger$ Range.

$\$$ Significance of the difference between controls and cirrhotics by the Mann-Whitney $U$ test.

"NS, $P>0.1$.

$S C$ in serum. Very high concentrations of total serum SC were found almost exclusively in patients with LD, particularly those with PBC, B Obst and A Hep. Small, but significant increases were also found in Sicca and RA (Fig. 1). There was no correlation between p-IgA, IgA2, or total IgA and total SC concentration in any patient group.

Subclass distribution of IgA in serum. Compared

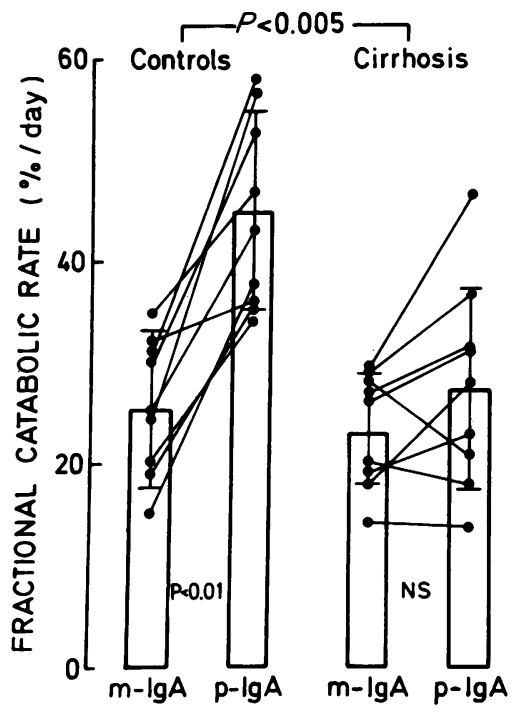

Figure 4 Fractional catabolic rates of $m$ - and $p$-IgA in controls $(n=9)$ compared to cirrhotics $(n=9)$. Means \pm SD are shown by columns. with controls with normal IgA levels, significant increases in the proportions of IgAl were found in connective tissue diseases and to a lesser extent in patients with CALD and Berger, whereas IgA2 percentages tended to be higher in patients with Crohn and Al C

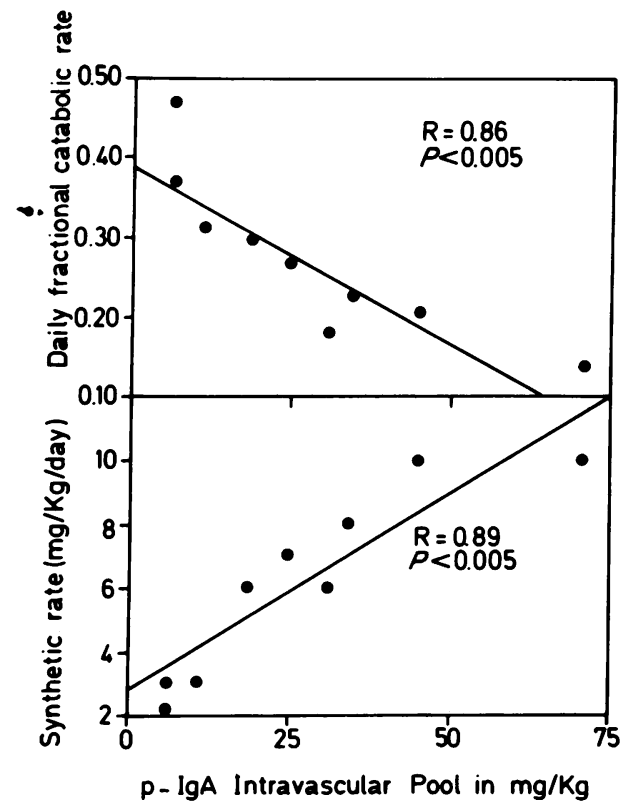

FIGURE 5 Regression lines of fractional catabolic rates of p-IgA (top) or of synthetic rates of p-IgA on the corresponding $\mathrm{p}$-IgA intravascular pool value. 
(Fig. 1D). In cirrhotics, patients with surgical portacaval shunt had values similar to those in other patients.

The increase of IgA2 relative to that of total IgA (regression slope \pm SD) was the highest in $\mathrm{Al} \mathrm{C}$ $(0.35 \pm 0.03)$ and Crohn's disease $(0.29 \pm 0.03)$. The

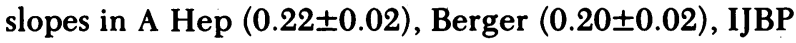
$(0.17 \pm 0.04)$, CALD $(0.17 \pm 0.02)$ and PBC $(0.17 \pm 0.02)$, were similar, close to that in controls alone $(0.22 \pm 0.05)$. The slope value in $\mathrm{Al} \mathrm{C}$ was significantly greater than that in each other LD $(P<0.05)$, and that in Crohn's disease greater than that in IJBP $(P<0.05)$. However, in connective tissue diseases, slopes (SLE, Sicca, and RA, each $0.09 \pm 0.02$ ) pointed to a marked shift ( $P$ $<0.001$ compared with any other disease category) of the subclass distribution to IgAl when total IgA increased. These differences are summarized in Fig. 3.

\section{DISCUSSION}

Heremans et al. first pointed out the presence of p-IgA in normal serum (33) at similar concentrations as in other mammals (2), but large additional amounts of $\mathrm{m}-\mathrm{IgA}$, not found in most mammals (34) make it the minor component of IgA in human serum. The higher proportions of plasma cells staining for p-IgA $(35,36)$ or for IgA2 (37) in mucosae than in bone marrow (35, $38)$, and the higher proportions of $p-\operatorname{IgA}(1,2)$ or of IgA2 $(6,7)$ in secretions than in serum, led some authors to regard serum p-IgA and/or IgA2 as being mainly of mucosal origin $(2,10,13)$. In contrast, mIgA and IgAl in serum are likely to originate predominantly from bone marrow (39) where IgAl plasmacytes predominate and are the largest producers of $\mathrm{m}$-IgA in vitro (40). However, when in vitro spontaneous secretion of IgA from cells is assessed, not only cells from lamina propria but also cells from peripheral lymph nodes and blood produce similar amounts with approximately equal proportions of $\mathrm{m}$ - and p-IgA (40). While in normal young infants and IgA deficient adults the size and the subclass distribution of IgA in serum vary independently (41), such data in disease are not available.

Tomasi and Grey (1) first reported an increased proportion of serum p-IgA in advanced LD. Since then variable increases of $\mathrm{p}$ - IgA have been reported in $\mathrm{Al}$ $C$ and also Berger's disease (10-14). The differences in the proportion of serum p-IgA reported in both patients and control populations are probably related to the methods and standards used for assaying IgA and to the failure to take into account the influence of the size of IgA on its immunoassays. These factors have been extensively analyzed by our laboratory and reported elsewhere $(25,27,28)$.

The present results confirm that elevations of total serum IgA may be found in a wide variety of diseases
(Fig. 1A). They demonstrate that such elevations can be accompanied either by a similar elevation of both m- and p-IgA (Berger's disease and B Obst) or by a more selective increase in $\mathrm{p}$-IgA as particularly in Sicca, intestinal diseases and parenchymal LD (Fig. 1B, Fib. 3). That the increase in p-IgA was not due to detection of $\mathrm{m}$-IgA present in immune complexes was confirmed by the stability at pH 3 and the appropriate J-chain content of the high molecular weight $\operatorname{IgA}$. Analysis of subclass distributions showed that an elevation of total serum IgA was accompanied by a preferential increase of IgAl in connective tissue diseases and to a lesser extent in Berger's disease and CALD (Fig. 1D). Although a statistically significant preferential increase in serum IgA2 was not demonstrated in any group compared to controls, a trend toward a shift to IgA2 was evident in Al C and Crohn's disease when compared with other diseases with elevated total serum IgA (Fig. 3).

In healthy controls our results show a 1.8 times greater FCR for p-IgA than for $\mathrm{m}-\operatorname{IgA}$, but also a higher synthetic rate for the $m$ - than for the $p$-IgA that reach the intravascular space. We think that the true p-IgA synthetic rate must be much larger than that reported here due to those molecules that never enter the circulating pool because of immediate local excretion at secretory sites. Both these differences in catabolism and synthetic rates explain the lower concentrations of p-IgA than of $\mathrm{m}$-IgA in serum of normal individuals.

In B Obst, there was no increase in serum p-IgA and, in the single patient studied, FCR of $\mathrm{m}$ - and pIgA were similar to mean FCR values in controls. We recently showed a selective plasma-to-bile transport of p-IgA in humans (29). However, we and others (29, 42) have shown that this transport is quantitatively much less important in humans than in rats and rabbits in which a major SC-dependent transhepatocyte transport of p-IgA occurs (43-45). Our present lack of serum p-IgA increase in human B Obst, unlike in rats and rabbits in which $B$ Obst results in a 10 times (or larger) increase in serum p-IgA $(45,46)$, is thus another argument for major species differences in hepatic transport of p-IgA into bile. It is likely that these species differences reflect differences in tissue distribution of SC in the liver: in human liver, SC was detected immunohistochemically only in and on bile duct cells $(47,48),{ }^{2}$ unlike its clearcut demonstration in and on rat and rabbit hepatocytes (49-51). Accordingly, the SC-dependent biliary transport of p-IgA in humans is probably restricted to bile duct cells. Our present data on B Obst as well as the previous isotopic studies (29,

\footnotetext{
${ }^{2}$ Delacroix, D. L., J. Rahier, M. Reynaert, J. P. Vaerman, and C. Dive. Submitted for publication.
} 
42) indicate that this bile duct cell transport plays little role in human plasma $\mathrm{p}$-IgA removal.

Our results in parenchymal LD, in contrast to those in B Obst, show a significant and preferential increase in serum p-IgA. In cirrhotics this preferential increase correlated with a selective reduction of the FCR of pIgA. This reduced p-IgA-FCR contrasts with the independence between serum IgA concentrations and IgA-FCR previously reported in other diseases (5255 ), and with the reported increased IgG-FCR in cirrhosis (56). This reduced p-IgA FCR cannot be explained by a reduced transport of serum p-IgA in various secretions since in a secretion such as saliva, 98\% of $\mathrm{p}$-IgA derive from local production and are independent from serum p-IgA (29). The changes in circulating p-IgA concentrations and FCR found in parenchymal LD but not in B Obst, suggest that the human liver may play a role in the selective removal of plasma p-IgA, but by another mechanism than the SCdependent bile duct cell transport into bile. Such a different, SC-independent mechanism would agree with the reported affinity of human hepatocytes for p-IgA but not for $\mathrm{m}$-IgA, independently of the presence of SC on the hepatocyte (48). The existence and nature of another putative receptor for p-IgA than SC on the human hepatocyte require further study.

Total SC in serum was increased almost specifically in LD with similar values as those previously reported $(23,57,58)$. The present data clearly show the lack of correlation between serum p-IgA and SC-concentrations in contrast to previous suggestions (11). The independence between these two serum parameters is well illustrated in B Obst, where very high serum SC concurred with normal serum p-IgA; and inversely in intestinal disease where high serum p-IgA concurred with virtually normal serum SC.

We have recently shown that SC in LD sera is not detectable in free form and is present bound to both p-IgA and IgM in proportion related to the serum pIgA/IgM molar ratio (21). This, and the presence in B Obst, of high serum concentrations of SC without increased p-IgA indicate that free SC may be released into the circulation from the diseased liver with subsequent binding to the polymeric immunoglobulins present in the circulation. Recent immunohistochemical data ${ }^{2}$ in fulminant hepatitis indicate that the portal and extraportal ductular proliferation (presumably neoformed bile ducts) probably plays a key role in the high serum SC concentrations in LD.

In nonliver diseases the increase in serum IgA concentration is most likely explained by an increased IgA production. Enhanced spontaneous secretion of IgA by peripheral blood mononuclear cells has been demonstrated in SLE and Crohn's disease (59), and increased IgA synthetic rates with normal FCR were reported in patients with inflammatory disease and high serum
IgA (53). A simultaneous preferential increase of both p-IgA and IgA2, suggestive of a mucosal origin of the elevated IgA, was found only in Crohn's disease in which a twofold increase of the number of IgA plasma cells in gut lamina propria occurs (60). However, in IJBP and Sicca, increase in P-IgA was associated with a preferential elevation of the IgAl subclass indicating that p-IgA and IgA2 in serum are also two independent parameters. There is evidence for prominent mucosal involvement in IJBP and Sicca $(61,62)$. Our data in these two disorders support that mucosal antigenic stimulation may result in a preferential p-IgA and IgAl increase in serum, similar to the pattern observed during the first months of life in infants who have up to $72 \%$ of $\mathrm{p}$-IgA in serum without increased proportion of IgA2 (41). However, regardless of the initial site of stimulation in these conditions, the tissue origin of the elevated serum IgA remains uncertain and could be nonmucosal. In SLE and RA a shift to IgAl was also found with sometimes high proportions of p-IgA although in these diseases mucosal involvement is not obvious. In Berger's disease, changes in size and subclass distribution of serum IgA were minimal. However, a small shift to IgAl subclass is more consistent with the reports of IgAl deposits in the glomerulus $(18,19)$. The tissue origin of the oversynthesized IgA in $\mathrm{LD}$ remains also uncertain. The particular contribution of IgA2 in $\mathrm{Al} \mathrm{C}$ contrasts with that of $\mathrm{IgAl}$ in CALD and suggests specific roles of the etiologic agents of the LD, rather than the direct role of LD itself, in the increased synthesis of IgA.

\section{ACKNOWLEDGMENTS}

The excellent technical assistance of J. Naze-De Mets, $R$ Meykens and J. P. Dehennin is gratefully acknowledged. We also thank Drs. E. Coche, F. Lavenne, J. B. Otte, and R. Fiasse for having allowed us to study their patients.

This work was supported in part by grants 3.4504 .70 and 220991 of the Fonds de la Recherche Scientifique Medicale, Brussels. Dr. Delacroix is Chargé de Recherches at the FNRS, Brussels.

\section{REFERENCES}

1. Tomasi, T. B., and H. M. Grey. 1972. Structure and function of immunoglobulin A. Progr. Allergy. 16: 81213.

2. Heremans, J. F. 1974. In The Antigens II. M. Sela, editor. Academic Press, Inc., New York. 423-440.

3. Kunkel, H. G., and R. A. Prendergast. 1966. Subgroups of $\gamma$ A immunoglobulins. Proc. Soc. Exp. Biol. Med. 122: 910-913.

4. Vaerman, J. P., and J. F. Heremans. 1966. Subclasses of human immunoglobulin A based on differences in the alpha polypeptide chains. Science (Wash. DC). 153: 647-649.

5. Feinstein, D., and E. C. Franklin. 1966. Two antigenically distinguishable subclasses of human $\gamma \mathrm{A}$ myeloma proteins differing in their heavy chains. Nature (Lond.). 212: 1496-1498. 
6. Grey, H. M., C. A. Abel, J. Yount, and H. G. Kunkel. 1968. A subclass of human $\gamma$ A-globulins $(\gamma$ A2) which lacks the disulfide bonds linking heavy and light chains. J. Exp. Med. 128: 1223-1236.

7. Delacroix, D. L., C. Dive, J. C. Rambaud, and J. P. Vaerman. 1982. IgA subclasses in various secretions and in serum. Immunology. 47: 383-385.

8. Brandtzaeg, P. 1981. Transport models for secretory IgA and secretory IgM. Clin. Exp. Immunol. 44: 221-232.

9. Nagura, H., P. K. Nakane, and W. R. Brown. 1979. Translocation of dimeric IgA through neoplastic colon cells in vitro. J. Immunol. 123: 2359-2368.

10. André, F., and C. André. 1976. Participation de l'immunoglobuline $\mathrm{A}$ monomérique et dimérique à l'hypergammaglobulinémie de la cirrhose éthylique. Biol. Gastroentérol. 9: 147-150.

11. Kutteh, W. H., S. J. Prince, J. D. Phillips, J. G. Spenney, and J. Mestecky. 1982. Properties of immunoglobulin A in serum of individuals with liver diseases and in hepatic bile. Gastroenterology. 82: 184-193.

12. Lopez Trascasa, M., J. Egido, J. Sancho, and L. Hernando. 1980. IgA glomerulonephritis (Berger's disease): evidence of high serum levels of polymeric IgA. Clin. Exp. Immunol. 42: 247-254.

13. André, C., F. C. Berthoux, F. André, J. Gillon, C. Genin, and J. C. Sabatier. 1980. Prevalence of IgA2 deposits in IgA nephropathies. A clue to their pathogenesis. N. Engl. J. Med. 303: 1343-1346.

14. Lesavre, Ph., M. Digeon, and J. F. Bach. 1982. Analysis of circulating IgA and detection of immune complexes in primary IgA nephropathy. Clin. Exp. Immunol. 48: 61-69.

15. Rifai, A., P. A. Small, P. O. Teague, and E. M. Ayoub. 1979. Experimental IgA nephropathy. J. Exp. Med. 150 1161-1173.

16. Unsworth, D. J., J. N. Leonard, A. W. Cayne, and L. Fry. 1982. IgA in dermatitis-herpetiformis skin is dimeric. Lancet. I: 478-479.

17. Sancho, J., J. Egido, M. Sanchez-Crespo, and R. Blasco. 1982. Detection of monomeric and polymeric IgA containing immune complexes in serum and kidney from patients with alcoholic liver disease. Clin. Exp. Immunol. 47: 327-335.

18. Conley, M. E., M. D. Cooper, and A. F. Michael. 1980. Selective deposition of immunoglobulin Al in immunoglobulin A nephropathy, anaphylactoid purpura nephritis, and systemic lupus erythematosus. J. Clin. Invest. 66: 1432-1436.

19. Tomino, Y., M. Endoh, Y. Nomoto, and H. Sakai. 1981. Immunoglobulin Al in IgA nephropathy. N. Engl. J. Med. 305: 19-20.

20. Thompson, R. A., and P. Asquith. 1970. Quantitation of exocrine IgA in human serum in health and disease. Clin. Exp. Immunol. 7: 491-500.

21. Delacroix, D. L., P. Jonard, C. Dive, and J. P. Vaerman. 1982. Serum IgM-bound secretory component (sIgM) in liver diseases: comparative molecular state of the secretory component in serum and bile. J. Immunol. 129: 133-138.

22. Delacroix, D. L., and J. P. Vaerman. 1982. Secretory component (SC): preferential binding to heavy (>11S) IgA polymers and IgM in serum, in contrast to predominance of $11 \mathrm{~S}$ and free SC forms in secretions. Clin. Exp. Immunol. 49: 717-724.

23. Delacroix, D. L., M. Reynaert, S. Pauwels, A. P., Geubel, and J. P. Vaerman. 1982. High serum levels of secretory IgA in liver disease: possible liver origin of the circulating secretory component. Dig. Dis. Sci. 27: 333-340.
24. Elkon, K. B., F. Caeiro, A. E. Gharavi, B. M. Patel, P. P. Ferjencik, and G. R. V. Hughes. 1981. Radioimmunoassay profile of antiglobulins in the connective tissue disorders: elevated levels of IgA antiglobulin in systemic Sicca syndrome. Clin. Exp. Immunol. 46: 547556.

25. Delacroix, D. L., and J. P. Vaerman. 1982. Influence of molecular size of IgA on its immunoassay by various techniques. III. Immunonephelometry. J. Immunol. Methods. 51: 49-55.

26. Delacroix, D. L., and J. P. Vaerman. 1981. A solid phase direct competition radioimmunoassay for quantitation of secretory IgA in human serum. J. Immunol. Methods. 40: $345-358$.

27. Delacroix, D. L., R. Meykens, and J. P. Vaerman. 1982. Influence of molecular size of IgA on its immunoassay by various techniques. I. Direct and reversed single radial immunodiffusion. Mol. Immunol. 19: 297-305.

28. Delacroix, D. L., J. P. Dehennin, and J. P. Vaerman. 1982. Influence of molecular size of IgA on its immunoassay by various techniques. II. Solid phase radioimmunoassays. J. Immunol. Methods. 48: 327-337.

29. Delacroix, D. L., H. J. F. Hodgson, A. McPherson, C. Dive, and J. P. Vaerman. 1982. Selective transport of polymeric IgA in bile. Quantitative relationship of monomeric and polymeric $\operatorname{IgA}, \operatorname{IgM}$ and other proteins in serum, bile and saliva. J. Clin. Invest. 70: 230-241.

30. Matthews, C. M. E. 1957. The theory of tracer experiments with ${ }^{131}$ I-labelled plasma protein. Phys. Med. Biol. 2: $36-53$.

31. Snedecor, G. W., and W. G. Cochran. 1978. In Statistical Methods. 6th edition. The Iowa University Press. Ames, Iowa. 128-132, 432-436.

32. Elkon, K. B., D. L. Delacroix, A. E. Gharavi, J. P. Vaerman, and G. R. V. Hughes. 1982. Immunoglobulin $A$ and polymeric IgA rheumatoid factors in systemic Sicca syndrome: partial characterization. J. Immunol. 129: 576581.

33. Heremans, J. F., M. T. Heremans, and H. E. Schultze. 1959. Isolation and description of a few properties of the $\beta 2 \mathrm{~A}$ globulin of human serum. Clin. Chim. Acta. 4: 96102.

34. Vaerman, J. P. 1970. Studies on IgA immunoglobulins in man and animals. Thesis. Sintal. Louvain, Belgium.

35. Radl, J., H. R. E. Schuit, J. Mestecky, and W. Hijmans. 1974. The origin of monomeric and polymeric forms of IgA in man. Adv. Exp. Med. Biol. 45: 57-65.

36. Brandtzaeg, P. 1973. Two types of IgA immunocytes in man. Nat. New Biol. 243: 142-143.

37. André, C., F. André, and M. C. Fargier. 1978. Distribution of IgAl and IgA2 plasma cells in various normal human tissues and in the jejunum of plasma IgA-deficient patients. Clin. Exp. Immunol. 33: 327-331.

38. Skvaril, F., and A. Morell. 1974. Distribution of $\operatorname{IgA}$ subclasses in sera and bone marrow plasma cells of 21 normal individuals. Adv. Exp. Med. Biol. 45: 433-435.

39. Benner, R., W. Hijmans, and J. J. Haaijman. 1981. The bone marrow: the major source of serum immunoglobulins, but still a neglected site of antibody formation. Clin. Exp. Immunol. 46: 1-8.

40. Kutteh, W. H., S. J. Prince, and J. Mestecky. 1982. Tissue origins of human polymeric and monomeric IgA. J. Immunol. 128: 990-995.

41. Delacroix, D. L., E. Liroux, and J. P. Vaerman. 1983. High proportion of polymeric IgA in young infants' sera and independence between IgA-size and IgA-subclass distributions. J. Clin. Immunol. In press. 
42. Dooley, J. S., B. J. Potter, H. C. Thomas, and S. Sherlock. 1982. A comparative study of the biliary secretion of human dimeric and monomeric IgA in the rat and in man. Hepatology. 2: 323-327.

43. Jackson, G. D. F., I. Lemaître-Coelho, J. P. Vaerman H. Bazin, and A. Beckers. 1978. Rapid disappearance from serum of intravenously injected rat myeloma IgA and its secretion into bile. Eur. J. Immunol. 8: 123-126.

44. Orlans, E., J. Peppard, J. Reynolds, and J. Hall. 1978. Rapid active transport of immunoglobulin A from blood to bile. J. Exp. Med. 147: 588-592.

45. Delacroix, D. L., A. M. Denef, G. A. Acosta, P. C. Montgomery, and J. P. Vaerman. 1982. Immunoglobulins in rabbit hepatic bile: selective secretion of IgA and IgM and active plasma to bile transfer of polymeric IgA. Scand. J. Immunol. 16: 343-350.

46. Lemaître-Coelho, I., G. D. F. Jackson, and J. P. Vaerman. 1978. High levels of secretory IgA and free secretory component in the serum of rats with bile duct obstruction. J. Exp. Med 147: 934-939.

47. Nagura, H., P. D. Smith, P. K. Nakane, and W. R. Brown. 1981. IgA in human bile and liver. J. Immunol. 126: $587-595$.

48. Hopf, U., P. Brandtzaeg, T. H. Hutteroth, and K. H. Meyer zum Büschenfelde. 1978. In vivo and in vitro binding of IgA to the plasma membrane of hepatocytes. Scand. J. Immunol. 8: 543-549.

49. Socken, S. J., K. N. Jeejeebhoy, H. Bazin, and B. J. Underdown. 1979. Identification of secretory component as an IgA receptor on hepatocytes. J. Exp. Med. 150: 1538-1548.

50. Kühn, L. C., and J. P. Kraehenbuhl. 1982. The membrane receptor for polymeric immunoglobulin is structurally related to secretory component. Isolation and characterization of membrane secretory component from rabbit liver and mammary gland. J. Biol. Chem. 256: 12490-12495.

51. Takahashi, I., P. K. Nakane, and W. R. Brown. 1982. Ultrastructural events in the translocation of polymeric IgA by rat hepatocytes. J. Immunol. 128: 1181-1187.

52. Strober, W., R. D. Wochner, M. H. Barlow, D. E.
McFarlin, and T. A. Waldmann. 1968. Immunoglobulin metabolism in ataxia telangiectasia. J. Clin. Invest. 47: 1905-1915.

53. Nadorp, J. H., M. Voss, P. J. Van Munster, G. Stoelinga, J. A. Flendrig, W. C. Buyd, and J. H. Van Tongeren. 1972. IgA metabolism in control subjects, in patients with elevated IgA levels and in patients with IgA deficiency. Protides Biol. Fluids Proc. Colloq. 19: 449-453.

54. Solomon, A., and T. B. Tomasi. 1964. Metabolism of IgA (B2A) globulin. Clin. Res. 12: 452a. (Abstr.)

55. Waldmann, T. A., and W. Strober. 1969. Metabolism of immunoglobulins. Progr. Allergy. 13: 1-10.

56. Eisenmenger, W. J. 1955. Hepatic function and protein metabolism in cirrhosis of the liver. Med. Clin. N. Am. 39: 719-734.

57. Thompson, R. A., R. Carter, R. P. Stokes, A. M. Geddes, and J. A. D. Goodall. 1973. Serum immunoglobulins, complement component levels and autoantibodies in liver diseases. Clin. Exp. Immunol. 14: 335-346.

58. Delacroix, D. L., and J. P. Vaerman. 1981. Reassessment of levels of secretory IgA in pathological sera using a quantitative radioimmunoassay. Clin. Exp. Immunol. 43: 633-640.

59. McDermott, R. P., G. S. Nash, M. J. Bertovich, M. V. Seiden, M. J. Bragdon, and M. G. Beale. 1981. Alteration of IgM, IgG and IgA synthesis and secretion by peripheral blood and intestinal mononuclear cells from patients with ulcerative colitis and Crohn's disease. Gastroenterology. 81: 844-852.

60. Baklien, K., and P. Brandtzaeg. 1975. Comparative mapping of the local distribution of immunoglobulin containing cells in ulcerative colitis and Crohn's disease of the colon. Clin. Exp. Immunol. 22: 197-209.

61. Drenich, E. J., M. E. Ament, and S. M. Finegold. 1976 Bypass enteropathy: intestinal and systemic manifestations following small-bowel bypass. J. Am. Med. Assoc. 236: 269-272.

62. Bloch, K. J., W. W. Buchanan, M. J. Wohl, and J. Bunim. 1965. Sjøgren's syndrome: a clinical, pathological and serological study of 62 cases. Medicine (Baltimore). 44: 187-231. 